\title{
Uptake of Galactose into Escherichia coli by Facilitated Diffusion
}

\author{
By H. L. KORNBERG* AND CLAUDIA RIORDAN† \\ Department of Biochemistry, School of Biological Sciences, \\ University of Leicester, Leicester $L E \mathrm{I} 7 R H$
}

(Received 27 October 1975)

\begin{abstract}
SUMMARY
Strains of Escherichia coli devoid of systems for the active transport of galactose ( $\mathrm{galP} \mathrm{mgl}$ ) still grow on galactose but at rates that are a function of the galactose concentration of the medium: half-maximal growth rates require more than $2 \mathrm{~mm}$-galactose to be present. Evidence is presented that galactose is taken up by such strains by facilitated diffusion on a carrier specified by the umg gene (or by a gene highly co-transducible with it) which is thus a part of, or closely associated with, an enzyme II for glucose of the phosphoenolpyruvate-phosphotransferase system. However, the entry of galactose does not require phosphotransferase activity, and the sugar taken up appears in the cells as free galactose.
\end{abstract}

\section{INTRODUCTION}

Studies with a variety of mutants indicate that Escherichia coli contains at least four distinct systems that can catalyse the active transport of D-galactose into the interior of the cell (reviewed by Lin, 1970), and that one of these, specified by the genetical marker $m g l$, probably contains more than one element (Ordal \& Adler, 1974a,b). The physiological roles of these different systems are not yet clear. It has been established (Wilson, 1974) that only two of them are induced by galactose; the others may thus be primarily involved in the uptake of other sugars, such as lactose, melibiose and arabinose. But all the systems share two properties: they have high affinities for galactose $\left(K_{m}<0.2 \mathrm{mM}\right)$, and they effect its translocation in a form chemically unchanged. In consequence, mutants devoid of galactokinase activity accumulate galactose as the free sugar against a concentration gradient (Horecker, Thomas \& Monod, I960). Activity of the phosphoenolpyruvate-linked phosphotransferase (PT) system that catalyses the uptake and simultaneous phosphorylation of sugars such as glucose, fructose and mannose (reviewed by Roseman, I969), thus appears not to be necessary for the utilization of galactose. Moreover, the activity of that system would lead to the formation of either galactose 6-phosphate or galactose I-phosphate. Membrane preparations of $E$. coli can catalyse the phosphoenolpyruvate-dependent uptake of galactose and its phosphorylation to galactose 6-phosphate (Kundig et al., 1965; Kaback, 1968; Roseman, I969), but no physiological role for galactose 6-phosphate has been found (Vorisek \& Kepes, 1972). This shows that there is no physiological means of by-passing the action of galactokinase to produce galactose I-phosphate; the formation of galactose Iphosphate by the PT system is therefore unlikely to play a significant role in $E$. coli.

During studies of the uptake of carbohydrate by $E$. coli strains, we noticed that most of the $\mathrm{F}^{-}$strains used were unable to catalyse the uptake of low concentrations of galactose

* Present address: Department of Biochemistry, University of Cambridge, Tennis Court Road, Cambridge CB2 IQW.

† Present address: Department of Genetics, University of Leeds, Leeds LS2 9JT. 
and of its analogues, methyl- $\beta$-D-galactoside and $\mathrm{D}$-fucose, that are characteristic of the specific and inducible systems for galactose transport, yet the apparently defective organisms grew readily on media containing glucose-free galactose as sole carbon source. This paper provides an explanation for this paradox and shows that galactose enters such $E$. coli strains by facilitated diffusion, catalysed by a protein that is either part of, or very closely associated with, a component of the PT system that also translocates methyl- $\alpha$-D-glucoside (Kornberg \& Smith, 1972; Kornberg \& Jones-Mortimer, 1975). However, whereas the uptake of methyl- $\alpha$-D-glucoside is accompanied by its phosphorylation to the 6-phosphate ester, with concomitant utilization of phosphoenolpyruvate, the uptake of galactose can proceed in the absence of a functioning PT system. This mode of utilization of galactose, whereby the galactose that thus diffuses into the cell is phosphorylated by ATP and galactokinase, requires rather high external concentrations of the sugar and may thus be readily distinguished from the 'true' galactose transport systems, whose affinity for galactose and its analogues is higher by at least an order of magnitude.

\section{METHODS}

Organisms. These are listed in Table $\mathrm{I}$. The abbreviations used to describe genetical markers are listed by Taylor \& Trotter (1972).

Unless stated otherwise, cells were grown aerobically at $37{ }^{\circ} \mathrm{C}$ on defined media containing salts (Ashworth \& Kornberg, 1966) and a carbon source at $0.2 \%(w / v)$; the media were supplemented as appropriate with required L-amino acids or pyrimidines at 40 to $100 \mu \mathrm{g} / \mathrm{ml}$. Growth was measured as the extinction of cell suspensions at $680 \mathrm{~nm}$; an $E_{680}$ of 1.0 was taken to represent $0.68 \mathrm{mg}$ dry mass/ml (Ashworth \& Kornberg, 1966; Kornberg \& Reeves, 1972).

Measurements of uptake of isotopically-labelled substrates. Cells were harvested in the mid-exponential phase of growth $(0.2$ to $0.6 \mathrm{mg}$ dry mass $/ \mathrm{ml})$ by centrifuging at $30000 \mathrm{~g}$ for $5 \mathrm{~min}$ at $15{ }^{\circ} \mathrm{C}$. They were washed once with nitrogen-free salts medium (Ashworth \& Kornberg, 1966), resuspended in the same medium to the required cell density (usually I to $2 \mathrm{mg}$ dry mass $/ \mathrm{ml}$ ) and stored in ice until required (o to $2 \mathrm{~h}$ ). Samples of this suspension were then shaken at $25^{\circ} \mathrm{C}$ for 10 min before the addition of labelled substrate. Where the labelled compound was a non-metabolizable sugar analogue, one-tenth volume of nutrient broth was also included. For the assay of $\mathrm{Mgl}$ activity, $\left[{ }^{14} \mathrm{C}\right]$ galactose at $0.5 \mu \mathrm{M}$ (Boos, 1969) or $\left[{ }^{14} \mathrm{C}\right]$ methyl- $\beta$-galactoside at $10 \mu \mathrm{M}$ were used; the concentrations of substrates used for other uptake measurements are given in the text. Samples $(0 \cdot 1 \mathrm{ml})$ were taken rapidly at suitable time intervals, filtered with suction through Millipore filters $(0.45 \mu \mathrm{m}$ pore size) and washed twice with $2 \mathrm{ml}$ of nitrogen-free salts medium at room temperature (20 to $22^{\circ} \mathrm{C}$ ). Filters were transferred to vials containing $5 \mathrm{ml}$ of Bray's (1960) fluid, and radioactivity was measured with a Packard model 3385 liquid scintillation spectrometer. [ $\left.{ }^{14} \mathrm{C}\right]$ Methyl- $\beta$ galactoside was purchased from NEN Chemical GmbH, Dreieichenhain, West Germany, and all other isotopic material from The Radiochemical Centre, Amersham, Buckinghamshire.

Purification of labelled galactose. It was found that both $\left[{ }^{3} \mathrm{H}\right]-$ and $\left[{ }^{14} \mathrm{C}\right]$ galactose as purchased were contaminated with traces of radioactive glucose which sufficed to introduce significant errors into measurements of galactose uptake by strains which have low transport activity for galactose. The method devised to purify the commercial material involved the use of strain $20 \mathrm{OSK}^{-}$, which has neither galactokinase activity nor an active transport system for galactose (Buttin, 1963a,b). However, the organism possesses constitutive glucose phosphotransferase activity (Kornberg \& Reeves, 1972) and therefore takes up glucose from the 
Table I. Organisms used

\begin{tabular}{|c|c|}
\hline Organism & Genetic markers \\
\hline \multicolumn{2}{|l|}{ Hfr strains } \\
\hline $\mathbf{K I}$ & met $B$ thy $A$ \\
\hline KIO & - \\
\hline KLI 6 & - \\
\hline KL96 & - \\
\hline tsig & met $B$ ptsI $I^{t_{s}}$ \\
\hline tsig.I $\Delta$ & metB ptsI crr \\
\hline BII & met $B$ \\
\hline \multicolumn{2}{|l|}{$\mathrm{F}^{-}$strains } \\
\hline $20 \mathrm{SOK}^{-}$ & galP galK $m g l$ str \\
\hline KRIOI & galP mgl str \\
\hline K2.It & galP mgl his argH thr leu pps str \\
\hline KRIOO & galP galK mgl his argH thr leu pps str \\
\hline KRI03 & galP mgl argH thr leu ptsI ${ }^{\text {ts }}$ str \\
\hline KRI05 & galP galK mgl his argH thr leu ptsI crr str \\
\hline KRI63 & galP mgl his argH thr leu pps (umg?) str \\
\hline KRI 64 & galP mgl his argH thr leu pps umg str \\
\hline K2.I.22 & galP mgl his argH thr leu pps umg str \\
\hline $\mathrm{K} 2.2 \mathrm{~W}$ & galP galK mgl his argH thr leu trp pps umg str \\
\hline $0144 \mathrm{~g}$ & galP mgl purB str \\
\hline OI $44-w g$ & galP mgl purB umg str \\
\hline $\mathrm{ABI} 325$ & galK $\mathrm{mgl}$ his proA purB lacY str \\
\hline ABI $325-W g$ & mgl his purB umg str \\
\hline W4345 & galK $\operatorname{mgl} \operatorname{lac} \Delta(I, Z, Y)$ \\
\hline
\end{tabular}

Reference or source

\author{
Laboratory stock \\ Laboratory stock \\ Laboratory stock \\ Laboratory stock \\ Bourd et al., (1971) \\ Jones-Mortimer \& Kornberg (1974a) \\ Laboratory stock \\ Buttin (1963a,b) \\ Derived from 20 sok- by transduction \\ with phage PI \\ Brice \& Kornberg (1967) \\ Derived from K2.It (see Methods) \\ Recombinant from [tsi $9 \times \mathbf{K 2 . 1}$ ] his $^{+}$ \\ Recombinant from [tsI9.I $\Delta \times$ KRIOO] \\ pps $^{+}$ \\ Thioglucose-resistant mutant of $\mathbf{k 2 . 1 t}$, \\ blackens film only faintly after ex- \\ posure to methyl- $\alpha-\left[{ }^{14} \mathrm{C}\right]$ glucoside \\ Thioglucose-resistant mutant of K2.It, \\ does not blacken film after exposure to \\ methyl- $\alpha-\left[{ }^{14} \mathrm{C}\right] \mathrm{glucoside}$ \\ From K2.It by the method of Kornberg \\ \& Smith (1972) \\ Kornberg \& Smith (1972) \\ Laboratory stock \\ From or 448 by selection for 3-deoxy- \\ 3-fluoroglucose resistance \\ Gift from A. L. Taylor \\ From ABI 325 by the method of Korn- \\ berg \& Smith (1972) to include umg, \\ followed by cross with Hfr KI and \\ selection for $\mathrm{gal}^{+} \mathrm{pro}^{+}$. \\ Rotman et al. (1968)
}

medium in preference to galactose and with high efficiency (Kornberg, 1973). Washed suspensions of glycerol-grown cells of strain $20 \mathrm{SOK}^{-}$were incubated with labelled galactose as purchased until no more radioactive material was taken up (about Io min). The cells were then filtered through a dry Millipore filter; the filtrate was essentially unaltered with respect to galactose concentration, and was glucose-free as judged from the inability of a fresh washed suspension of strain $20 \mathrm{OSOK}^{-}$to incorporate labelled material from this preparation into cellular constituents.

Assay of $\beta$-galactosidase. $\beta$-Galactosidase activity was measured as the rate at which toluenized cells hydrolysed $o$-nitrophenyl- $\beta$-galactopyranoside (ONPG) at $30{ }^{\circ} \mathrm{C}$, as described by Hestrin, Feingold \& Schramm (I955).

Genetical procedures. In general, the genetical procedures used were those described by Miller (1972). Strains impaired in Umg activity were selected as mutants that grew on $5 \mathrm{mm-}$ fructose despite the presence of $5 \mathrm{mM}$-2-deoxyglucose or of $0.5 \mathrm{mM}$-5-thio-D-glucose, by the procedure used by Kornberg \& Smith (1972); ctr crr strains were isolated as described by Jones-Mortimer \& Kornberg (1974a).

The derivative of strain K2.It devoid of galactokinase ( $\mathrm{galK}$ ) was obtained by $\lambda$-eduction, according to Shimada, Weisberg \& Gottesman (1972), to make a biotin auxotroph which 


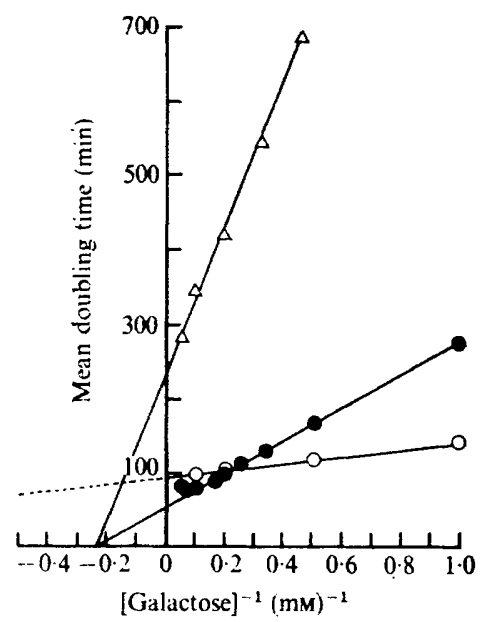

Fig. I

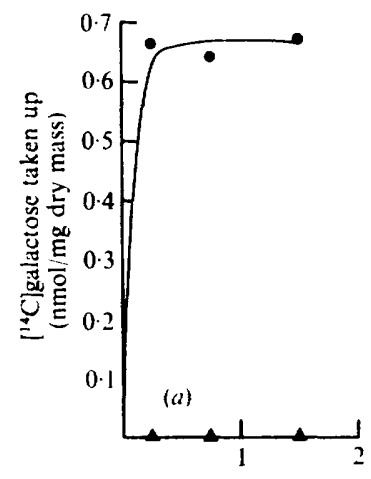

Time $(\mathrm{min})$

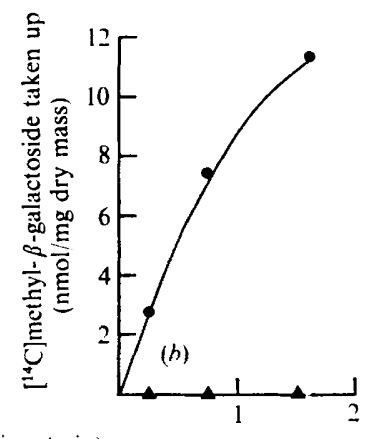

Fig. 2

Fig. 1. Effect of galactose concentration on the growth rate of different strains of $E$. coli. The strains tested were $(\bigcirc) \mathrm{KL1} 6,\left(O_{)} \mathrm{K2.1}\right.$ t, and $(\triangle) \mathrm{K} 2.1 .22$ (umg). The mean doubling time is plotted against the reciprocal of the galactose concentration.

Fig. 2. The uptake of $(a) 0.5 \mu_{\mathrm{M}}-\left[{ }^{14} \mathrm{C}\right]$ galactose and $(b)$ 10 $\mu_{\mathrm{M}-}\left[{ }^{14} \mathrm{C}\right]$ methyl- $\beta$-galactoside by washed suspensions of galactose-grown $E$. coli strains $(\Theta)$ KL16 and $(\Delta)$ K2.It.

was then transduced to galK. A culture of strain K2.It was lysogenized with phage $\lambda c I 857$, which makes a temperature-sensitive repressor and therefore can exist as a stable prophage at the permissive temperature $\left(30^{\circ} \mathrm{C}\right)$, but enters the lytic cycle at the restrictive temperature $\left(42^{\circ} \mathrm{C}\right.$ ). By screening for resistance to $\lambda$ vir at $30^{\circ} \mathrm{C}$, a spontaneous $\lambda$-resistant mutant of the lysogen was obtained. Samples $(0.1 \mathrm{ml})$ of an overnight culture of this organism were spread on nutrient agar plates and incubated at $42{ }^{\circ} \mathrm{C}$. For the host to survive under these conditions the prophage must be unable successfully to enter the lytic cycle, a condition which obtains if phage genes - together, perhaps, with adjacent bacterial genes - have been lost. None of the educants thus obtained was galactose-negative, but several biotin-requiring (bio) mutants were isolated. One of these was infected with phage PI propagated on strain $2 \mathrm{OSOK}^{-}(\mathrm{galK})$; selection for $\mathrm{bio}^{+}$yielded transductants carrying the defective $\mathrm{galK}$ allele of strain $2 \mathrm{OSOK}^{-}$.

\section{RESULTS AND DISCUSSION}

\section{Growth of $E$. coli on galactose}

Although all strains of $E$. coli KI 2 not impaired in the enzymes of galactose utilization specified by the gal operon grow on media containing galactose as sole carbon source, they differ markedly in growth rate on low concentrations of that sugar. The strains that were examined fell into two distinct classes. One class, typified by the genetic donor (Hfr) strains KI (HfrH), KIO (HfrC), KL96 and KLI6, grew readily on media containing the lowest concentrations of galactose at which measurements of growth rates in batch culture were feasible ( $\mathrm{I} \mathrm{mM}$ ); increases in the galactose concentration of the medium (up to $20 \mathrm{~mm}$ ) increased only slightly the rates of growth. The other class, illustrated by the $\mathrm{F}^{-}$strains K2. It and oI44g, grew poorly on media containing galactose at $3 \mathrm{~mm}$ or less, but grew readily when galactose was supplied at $10 \mathrm{~mm}$ or higher. A plot of the mean doubling time 


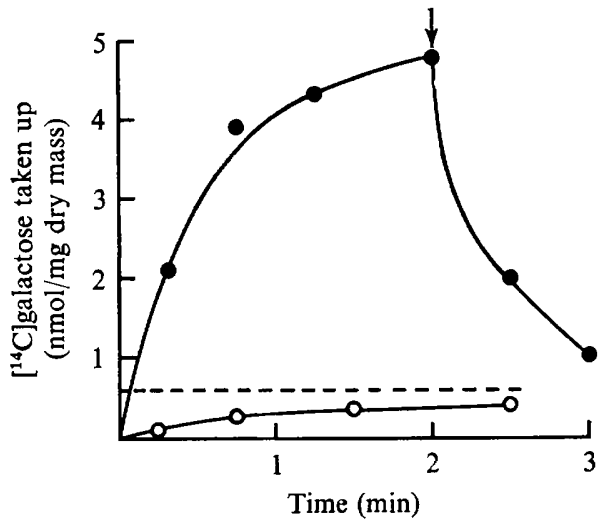

Fig. 3

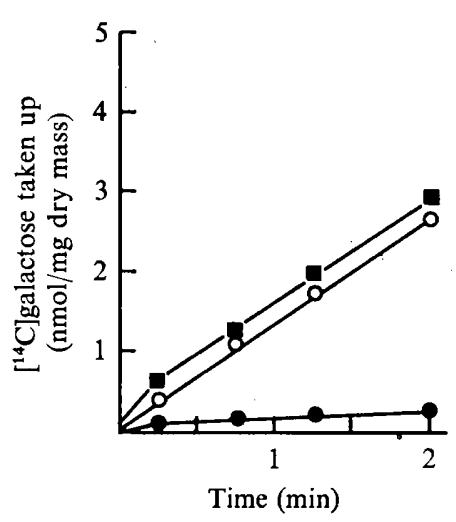

Fig. 4

Fig. 3. Uptake of $0 \cdot 2 \mathrm{~mm}-\left[{ }^{14} \mathrm{C}\right]$ galactose by the galK strains (O) W4345 and (O) KRIOO. Unlabelled galactose (to $20 \mathrm{~mm}$ ) was added to the suspension of strain $\mathbf{w} 4345$ at the point indicated by an arrow. The dotted line represents the galactose content of the cells calculated for $0.2 \mathrm{~mm}$ in the cell water.

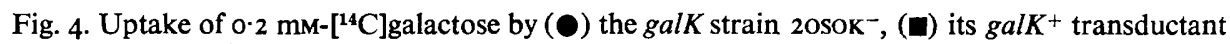
KRIOI, and $(O)$ the galK $^{+}$strain K2.I t.

against the reciprocal of the initial galactose concentration in the medium gave straight lines. As shown in Fig. I, these lines can be extrapolated to cut the abscissa at points which, by analogy with Lineweaver-Burk plots, would correspond to the negative reciprocal of the galactose concentrations at which half the maximal growth rate would be achieved. The ' $K_{m}$ ' values that are calculated from the data thus obtained are a measure of the affinity for galactose of the overall growth process. The first class of organism has a much higher affinity for galactose as a growth substrate (' $K_{m}$ ' about $0.6 \mathrm{mM}$ ) than does the second (' $K_{m}$ ' about $4 \mathrm{mM}$ ). Since the rate at which galactose enters the cell is the limiting step of galactose utilization (Horecker et al., 1960), these results also suggest that, at low concentrations of galactose, the second class of organism may take up galactose less readily than would the first.

Studies with washed suspensions of galactose-grown cells bear out this expectation. Taking strains KLI6 and K2.It as representative of the two classes, Fig. 2 shows that suspensions of the latter organism take up neither $0.5 \mu \mathrm{M}-\left[{ }^{14} \mathrm{C}\right.$ lgalactose nor ${ }^{2} \mu \mu \mathrm{M}-\left[{ }^{14} \mathrm{C}\right]-$ methyl- $\beta$-galactoside even though the cells had grown on galactose. In contrast, similar suspensions of strain KLI6 take up both labelled materials rapidly. These differences are characteristic of the expression of alleles of the $m g l$ genes (Boos, 1969; Ordal \& Adler, I $974 a, b$ ). It is evident that strain KLI6 and other strains with a low ' $K_{m}$ ' for growth on galactose are $\mathrm{Mgl}^{+}$, whereas strain $\mathrm{K2}$.It, and other strains with a high ' $K_{m}$ ' for growth on galactose, are $\mathrm{Mgl}^{-}$.

A second system specifically involved in the uptake of galactose is that specified by the galP gene (Rotman, Ganesan \& Guzman, 1968) which was identified in an E. coli strain w4345 devoid both of galactokinase ( $\mathrm{g} a \mathrm{l} \mathrm{K}$ ) and of $\mathrm{Mgl}$ activity. Suspensions of this organism, induced by growth in the presence of $\mathrm{D}$-fucose, readily take up galactose when incubated with $0.2 \mathrm{mM}-\left[{ }^{14} \mathrm{C}\right]$ galactose (Fig. 3 ); when unlabelled galactose is added, the radioactive material taken up is rapidly washed out of the cells. This shows that the $\mathrm{galP}^{+}$strain accumulates free galactose to about $5 \mathrm{nmol} / \mathrm{mg}$ dry mass. On the assumption that I mg dry mass of cells can be equated with $3 \mu 1$ of cell water (Roberts et al., 1955; Winkler \& Wilson, 1966), this corresponds to an accumulation of labelled galactose to $1.6 \mathrm{~mm}$ before the 

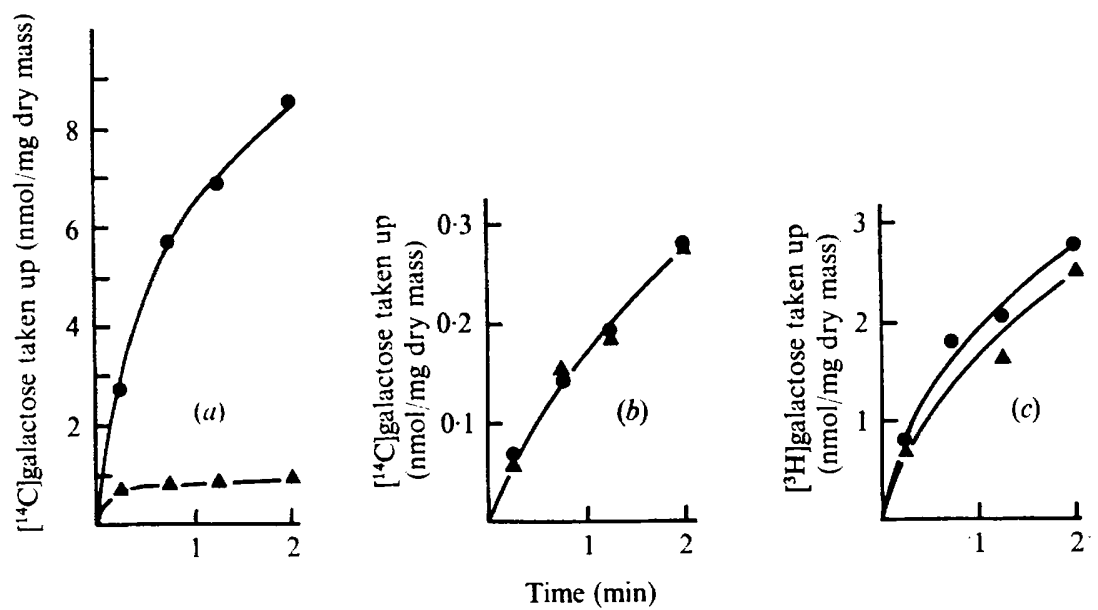

Fig. 5. Effect of CCCP on galactose uptake by galP+ and galP strains of $E$. coli. The uptake of $0.2 \mathrm{mM}^{-}\left[{ }^{14} \mathrm{C}\right]$ galactose by strains $(a)$ W4345 $\left(\mathrm{galP}^{+}\right)$and $(\mathrm{b}) 20 \mathrm{SOK}^{-}(\mathrm{galP})$, and $(\mathrm{c})$ the uptake of $2 \mathrm{mM}-\left[{ }^{3} \mathrm{H}\right]$ galactose by strain 20 sok ${ }^{-} .0$, Washed suspensions; $\Delta$, suspensions supplemented with $20 \mu \mathrm{M}-\mathrm{CCCP}$.

unlabelled material was added, which is eight times greater than the galactose concentration of the medium.

The absence of the GalP system from strain K2. It could not be demonstrated directly with this organism, since any galactose taken up would be metabolized. However, a derivative of strain K2.It, designated KRIOO, was prepared that lacked galactokinase activity; suspensions of this strain, induced by growth in the presence of $\mathrm{D}$-fucose, took up labelled galactose at a slow rate and to an extent approaching the galactose concentration of the medium. Clearly, strain KR 100 lacks the mechanism for active transport of galactose specified by the galP $^{+}$allele present in strain W4345. It is reasonable to assume that strain $\mathrm{K2}$.It, from which strain KRI00 was derived, lacks GalP activity; although the galK allele of strain KRIOO was introduced by transduction with phage PI propagated on strain $20 \mathrm{OSO}^{-}$, there is good evidence that the galP marker maps far from other markers of the gal operon (Buttin, $1963 b$ ). Moreover, the strain of $E$. colidesignated 20soK- (Buttin, 1963a,b) is known to lack galactokinase activity and to be devoid of both the systems specified by the $m g l^{+}$and galP $^{+}$alleles (Rotman et al., I968). When suspensions of this strain, grown in the presence of D-fucose as inducer of galactose uptake, were exposed to $0.2 \mathrm{~mm}-\left[{ }^{14} \mathrm{C}\right]$ galactose, the rate and extent of uptake of this sugar were similar to those noted with strain KR IO0. Furthermore, when this strain was transduced to $g a l K^{+}$by phage PI propagated upon strain $\mathrm{K} 2 . \mathrm{It}$, the properties of the resultant transductant KRIOI were indistinguishable from those of the galK ${ }^{+}$strain $\mathrm{K2} . \mathrm{It}$, both with respect to the uptake of $0.2 \mathrm{~mm}-\left[{ }^{14} \mathrm{C}\right]$ galactose (Fig. 4) and with respect to growth on galactose. As expected from the absence of the $\mathrm{Mgl}$ system, neither strain took up Io $\mu \mathrm{M}-\left[{ }^{14} \mathrm{C}\right]$ methyl- $\beta$-galactoside. It can thus be concluded that $E$. coli strains such as $20 \mathrm{OSOK}^{-}, \mathrm{K} 2 . \mathrm{It}$, and others that are both $\mathrm{galP}$ and $\mathrm{mgl}$, take up galactose via some other transport system(s).

Three further systems have been described that can catalyse the active transport of galactose. The set of activities specified by the lac operon includes the permease that facilitates the uptake of numerous $\beta$-galactosides. This lac permease is induced by galactose in strains lacking galactokinase (Kalckar, Kurahashi \& Jordan, I959; Wu, 1967); however, no 
such induction of the lac permease occurs during the growth on galactose of $E$. coli strains that are galK $^{+}$(Rotman et al., I968). We confirm this: no significant $\beta$-galactosidase activity was detected in toluene-treated suspensions of strain K2.It after its growth on galactose, although activity was rapidly induced when $\mathrm{I}$ mM-isopropylthiogalactoside was added to a culture growing on galactose.

The main uptake system for arabinose, which is also capable of transporting galactose, was not found in our strains of the organism when grown on galactose. Similarly, the melibiose transport system could not have accounted for the observed utilization of galactose since this system does not operate at $37^{\circ} \mathrm{C}$ in $\mathrm{KI} 2$ strains of $E$. coli (Rotman et al., I968).

The active transport of carbohydrates, which enables these substances to be taken up and (in suitably blocked mutants) to be accumulated, chemically unchanged, to high internal concentrations, depends on the maintenance of chemical and electrical gradients across cell membranes (Mitchell, 1970, 1973; Harold, 1972). These gradients are abolished by protonconducting agents, such as carbonylcyanide- $m$-chlorophenylhydrazone (CCCP). As shown in Fig. 5, $20 \mu \mathrm{M}$-CCCP markedly inhibited the uptake of $0.2 \mathrm{mM}$-galactose by the galP+ strain w4345 but had no significant effect on the much lower rate and extent of galactose uptake by strain $20 \mathrm{oK}^{-}$, either at 0.2 or $2 \mathrm{mM}$. This confirms that the uptake of galactose by organisms devoid of GalP and $\mathrm{Mgl}$ activities does not involve an active transport process.

\section{Growth on galactose and the uptake of methyl- $\alpha-\mathrm{D}-$ glucoside}

It has been shown (Roseman, 1969) that the growth of $E$. coli on sugars such as fructose, mannose, mannitol and glucose requires the functioning of a phosphoenolpyruvatedependent PT system, in which an enzyme I catalyses the transfer of the phosphate group from phosphoenolpyruvate to a small histidine-containing protein (abbreviated HPr). The resultant phospho-HPr can then donate this phosphate to a terminal hydroxyl group of the appropriate sugar. This final step, that results in the formation of the sugar-phosphate, is catalysed by one or more enzymes II. In the case of glucose, two such enzymes II have been identified. One, specified by a gene designated umg by Kornberg \& Smith (1972) and gpt $A$ by Curtis \& Epstein (1970), effects also the uptake and phosphorylation of the noncatabolizable glucose derivative methyl- $\alpha$-D-glucoside. The other, originally designated gpt $B$ by Curtis \& Epstein (1970) and probably identical with the pts $X$ gene involved also in fructose uptake (Jones-Mortimer \& Kornberg, I974 b; Kornberg \& Jones-Mortimer, 1975), appears not to effect the uptake of that analogue although it is involved in the transport (and phosphorylation) of 2-deoxy-D-glucose as well as of glucose. The relative proportions of these two enzymes II vary in strains of $E$. coli; in the $\mathrm{F}^{-}$strain K2.It (and the similar strain oI $44 \mathrm{~g}$ ), well over $60 \%$ of the total glucose taken up enters via the Umg system (Kornberg, I972; Kornberg \& Jones-Mortimer, I975; Amaral \& Kornberg, 1975). It follows that mutation of such organisms to $u m g$ markedly impairs their rates of growth on glucose: there is a striking increase in doubling time, from about $60 \mathrm{~min}$ at $37^{\circ} \mathrm{C}$ to over $3 \mathrm{~h}$. Growth on other hexoses (such as mannose, mannitol or fructose) that are also taken up via the PT system but do not involve the activity of the Umg component, is not impaired. However, growth on galactose, which is not thought to be taken up via the PT system, is strongly affected. As shown in Fig. I, this slower growth on galactose is a consequence of a reduction in the maximal growth rate and not in the affinity (' $K_{m}$ ') of some rate-limiting step for galactose.

Evidence that this impairment in growth on galactose or glucose, and in ability to take up methyl- $\alpha$-D-glucoside, are the consequence of one mutational event can be summarized as follows: 
(i) umg mutants do not blacken X-ray film when, after growth on nutrient agar supplemented with $10 \mu \mathrm{M}$-methyl- $\alpha-\mathrm{D}-\left[{ }^{14} \mathrm{C}\right]$ glucoside, they are applied to such film (Kornberg \& Smith, 1972). Revertants to $\mathrm{umg}^{+}$, selected for ability to grow rapidly on glucose, regain the ability to blacken film and simultaneously regain the ability to grow rapidly on $5 \mathrm{~mm}-$ galactose as well as on $5 \mathrm{~mm}$-glucose.

(ii) Revertants of umg mutants selected for their ability to grow rapidly on galactose are of two main types. One type remains umg: this mainly consists of mutants that have become constitutive for the enzymes of the lac operon. However, the other type is $u \mathrm{~m}^{+}$: mutation to better growth on galactose appears simultaneously also to relieve the impairment to uptake of glucose via this system.

(iii) The umg gene is about $20 \%$ cotransducible with purB (Kornberg \& Smith, 1972). The $\mathrm{F}^{-}$strains $0144^{-W g}$ and $\mathrm{ABI}^{-} 325-\mathrm{Wg}$ carry both these markers and, in consequence, require adenine for growth, do not blacken film, and grow poorly both on glucose and on galactose. After infection with phage PI propagated on E. coli strain K2.It $\left(u m g^{+}\right.$pur $\left.B^{+}\right)$, pur $^{+}$transductants were selected; these were either $u m g^{+}$(recognized by their ability to blacken film) or had remained umg. All of 7 I $u m g^{+}$transductants tested had simultaneously regained the wild-type ability to grow on glucose and on galactose whereas none of the approximately $400 \mathrm{umg}$ colonies grew well on either hexose.

(iv) Measurements of the uptake of $\left[{ }^{14} \mathrm{C}\right]$ galactose by suspensions of cells inducible for the Umg system (Kornberg \& Reeves, 1972), further support a role of this system in the growth on galactose of $E$. coli strains devoid of GalP and $\mathrm{Mgl}$ activities. Washed suspensions of such strains, grown on gluconate, took up little methyl- $\alpha-\mathrm{D}-\left[{ }^{14} \mathrm{C}\right]$ glucoside; they also took up little $\left[{ }^{14} \mathrm{C}\right]$ galactose at either 0.2 or $2 \mathrm{mM}$. However, similar suspensions of the cells grown on glucose readily took up methyl- $\alpha-\mathrm{D}-\left[{ }^{14} \mathrm{C}\right]$ glucoside: they also took up $2 \mathrm{mM}-$ $\left[{ }^{14} \mathrm{C}\right]$ galactose at a significantly faster rate, although not previously exposed to this hexose.

\section{The role of the Umg system in galactose uptake by galP $\mathrm{mgl}$ strains of $E$. coli}

The protein(s) specified by the umg gene normally act as the final component (enzyme II) of the PT system that effects the translocation and phosphorylation of glucose and its analogue methyl- $x$-D-glucoside. The question thus arises whether the involvement of this enzyme II in the utilization of galactose by some $E$. coli strains indicates a role of phosphotransferase activity in galactose uptake. In addition to the evidence discussed in the Introduction, there are several observations against this:

(i) The addition of pyruvate to cultures of $E$. coli strains devoid of phosphoenolpyruvate synthetase (pps) (Cooper \& Kornberg, 1967; Brice \& Kornberg, 1967) results in a pronounced decrease in their rate of growth if those cultures are growing on a sugar necessarily taken up via the PT system, such as fructose, glucose, mannitol or mannose, but not if the substrate is a carbohydrate taken up by some other means, such as glucose 6-phosphate, gluconate, arabinose or lactose (Morgan \& Kornberg, 1967). Galactose falls into this latter category. Pyruvate does not inhibit the growth on galactose, nor the uptake of $\left[{ }^{14} \mathrm{C}\right]$ galactose, by $E$. coli strains that are pps even if they also lack the $\mathrm{Mgl}$ and GalP systems.

(ii) A direct comparison between the activities of an organism with and without a functioning PT system is provided by studies with the $m g l$ galP strain KRIO3. This organism is a recombinant from a genetic cross of the $\mathrm{F}^{-}$strain $\mathrm{K2}$. It with the $\mathrm{HfrC}$ strain ts 19 , which is a mutant with a temperature-sensitive enzyme I of the PT system (Bourd et al., I97I). The recombinants used took up neither $0.5 \mu \mathrm{M}-\left[{ }^{14} \mathrm{C}\right]$ galactose nor ${ }^{10} \mu \mathrm{M}-\left[{ }^{14} \mathrm{C}\right]$ methyl- $\beta$-Dgalactoside, which confirmed the absence of the $\mathrm{Mgl}$ system. The uptake of $0 \cdot 2 \mathrm{~mm}-\left[{ }^{14} \mathrm{C}\right]-$ galactose by these recombinants at $25{ }^{\circ} \mathrm{C}$ occurred at the same rate and to the same extent 


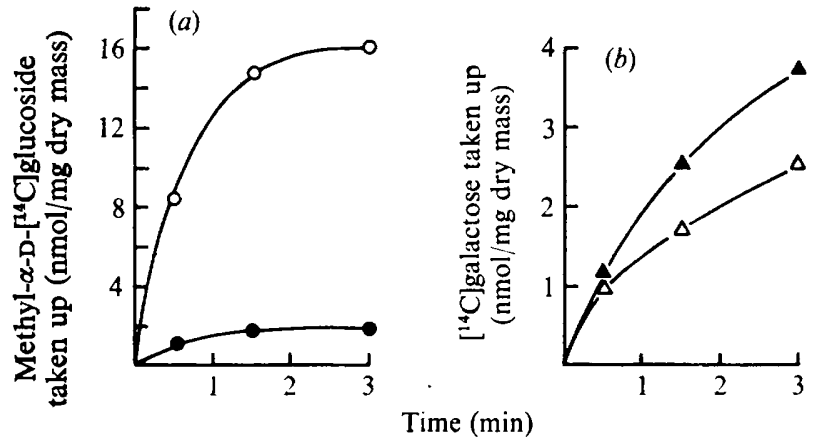

Fig. 6. Uptake of $(a) 0.1$ mM-methyl- $\alpha-D-\left[{ }^{14} \mathrm{C}\right]$ glucoside and $(b) 0.2 \mathrm{~mm}-\left[{ }^{14} \mathrm{C}\right]$ galactose, by suspensions of strain KRIO3 which had been grown on galactose at $30^{\circ} \mathrm{C}$. The suspensions were incubated with the labelled substrates at $30^{\circ} \mathrm{C}$ (open symbols) and at $42{ }^{\circ} \mathrm{C}$ (closed symbols).
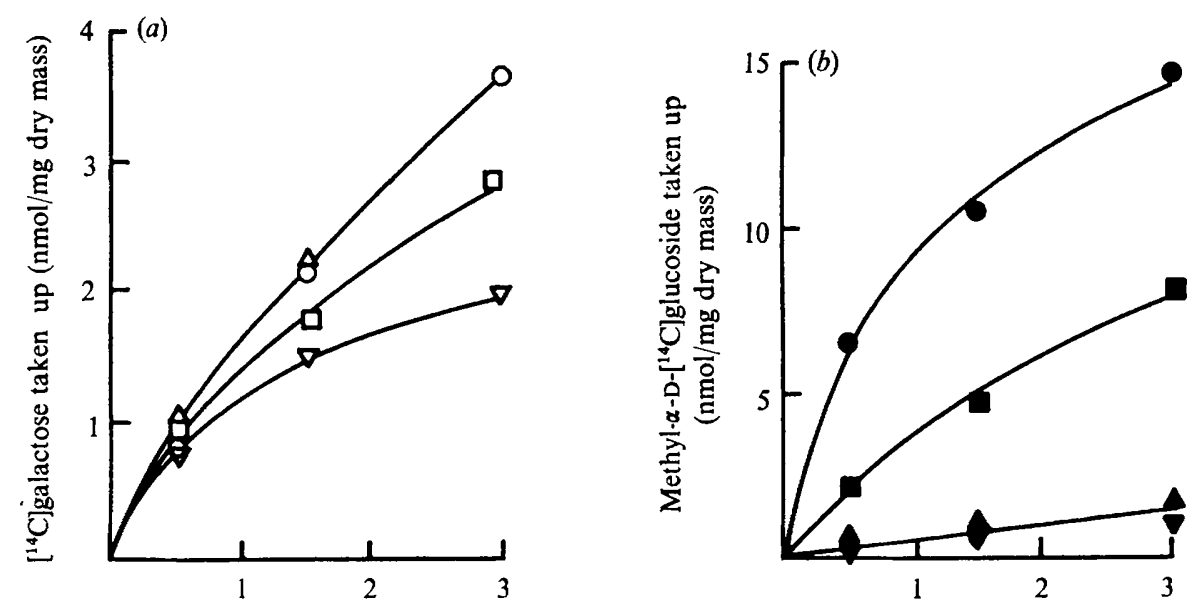

Time (min)

Fig. 7. Uptake of $(a) 0.2 \mathrm{~mm}-\left[{ }^{14} \mathrm{C}\right]$ galactose (open symbols) and (b) $0.1 \mathrm{~mm}-\mathrm{methyl}-\alpha-\mathrm{D}-\left[{ }^{14} \mathrm{C}\right]-$ glucoside (closed symbols) by suspensions of strain KRIO3 growing on IO mM-galactose initially at $30^{\circ} \mathrm{C}$ and then transferred to $40^{\circ} \mathrm{C}$. Samples were taken $(O, \odot)$ immediately and $(\square, \square) 60 \mathrm{~min}$, $(\triangle, \Delta) 195 \mathrm{~min}$, and $(\nabla, \nabla) 260 \mathrm{~min}$ after transfer to the higher temperature.

as it did with suspensions of the $\mathrm{F}^{-}$parent organism $\mathrm{K2}$.It, which confirmed the absence of the GalP system. Like its male parent, suspensions of the recombinant strain KRIO3 take up $0.1 \mathrm{mM}$-methyl- $\alpha$-D-[ $\left[{ }^{14} \mathrm{C}\right]$ glucoside readily if the cells are grown at $30^{\circ} \mathrm{C}$ and are then exposed to this labelled substrate at temperatures below $30^{\circ} \mathrm{C}$; however, they do not take up methyl- $\alpha$-D- $\left[{ }^{14} \mathrm{C}\right]$ glucoside at $42{ }^{\circ} \mathrm{C}$. In contrast, the uptake of $\left[{ }^{14} \mathrm{C}\right]$ galactose, by suspensions of cells grown on $10 \mathrm{~mm}$-galactose at $30{ }^{\circ} \mathrm{C}$, is more rapid at $42{ }^{\circ} \mathrm{C}$ than it is at $30{ }^{\circ} \mathrm{C}$ (Fig. 6). Moreover, if cells grown on galactose at $30^{\circ} \mathrm{C}$ are incubated at $42{ }^{\circ} \mathrm{C}$ for $30 \mathrm{~min}$ before measurement of the uptake of labelled substrates, the uptake of methyl- $\alpha-D-\left[{ }^{14} \mathrm{C}\right]-$ glucoside is virtually abolished as a result of the heat-denaturation of enzyme I activity. In contrast, the uptake of $0.2 \mathrm{~mm}$ - or $4 \mathrm{mM}-\left[{ }^{14} \mathrm{C}\right]$ galactose is little affected by this treatment. That this phenomenon applies also to cells growing on galactose is shown in Fig. 7: samples taken from a culture growing on 10 mM-galactose, that was switched from 30 to $40^{\circ} \mathrm{C}$, showed a rapid loss of ability to take up methyl- $\alpha-\mathrm{D}-\left[{ }^{14} \mathrm{C}\right]$ glucoside (and $\left[{ }^{14} \mathrm{C}\right]$ glucose) which 


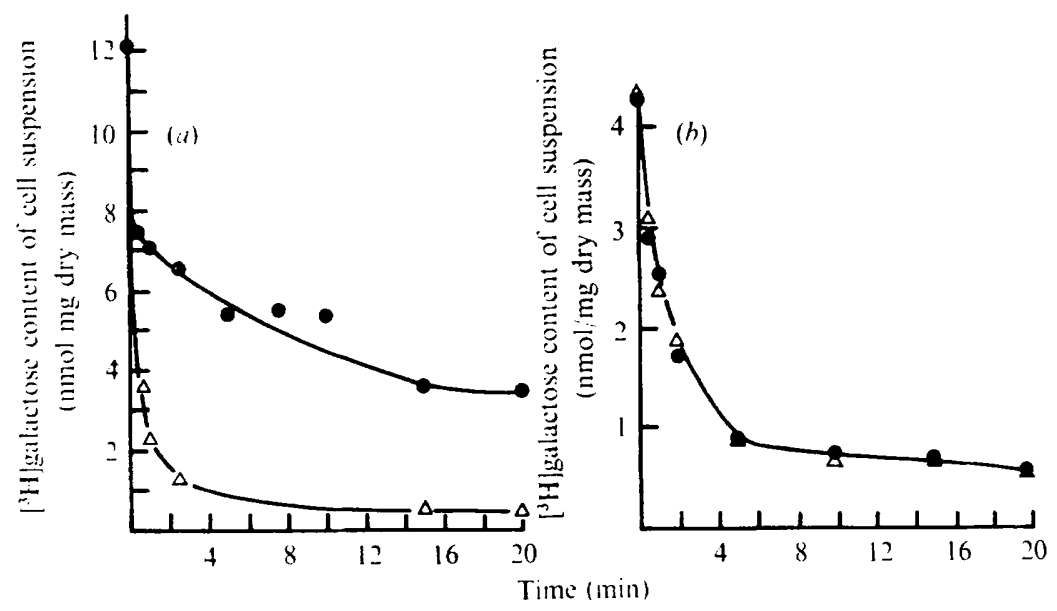

Fig. 8. Efflux of $\left[{ }^{3} \mathrm{H}\right]$ galactose from suspensions of: (a) strain $\mathrm{w}_{4345}\left(\mathrm{galK} \mathrm{galP} \mathrm{P}^{+}\right.$) when diluted at $30^{\circ} \mathrm{C}$ into (O) 10 vol. of salts solution, or $(\hat{\Delta}) 10$ vol. of $4 \mathrm{~mm}$ unlabelled galactose; $(b)$ strain $\mathrm{KR} 100(\mathrm{gal} K \mathrm{galP})$ when diluted at $30^{\circ} \mathrm{C}$ into $(\odot) 100$ vol. of salts solution or $(\triangle) 100$ vol. of $2 \mathrm{~mm}$ unlabelled galactose.

considerably preceded the much slower and less dramatic heat-denaturation of the galactoseuptake system.

(iii) Although these findings argue against any necessary role of the phosphoenolpyruvatephosphotransferase system in the uptake of galactose by $E$. coli, there is a possible source of error in experiments with mutants devoid of enzyme I activity. It is known that such mutants may fail to grow on sugars such as maltose, lactose and galactose, as well as on glycerol and succinate, which are known not to be taken up by the PT system (Kamogawa \& Kurahashi, 1967; Wang \& Morse, 1968; Bourd et al., 1969). This failure to grow has been ascribed to an undue susceptibility of these mutants to catabolite repression, with the consequence that the growth substrates fail effectively to induce the systems required for their uptake and metabolism (Epstein, Jewett \& Winter, 1970; Saier \& Roseman, 1972; Roseman, 1975). Many $E$. coli mutants of this type revert to growth on some or all of these substrates without regaining a functioning phosphotransferase system (Wang, Morse \& Morse, 1970). One such revertant strain, designated tsi9.I $\Delta$, was isolated from the $\mathrm{HfrC}$ strain ts 19 by JonesMortimer \& Kornberg (1974a); it carries a deletion of that region of the genome covering the gene specifying enzyme I activity ( $p t s I)$ and the gene involved in the failure of non-PT sugars to induce their respective uptake systems. Alteration in this latter gene confers on the cell resistance to repression by carbohydrates and it has been designated $\mathrm{cr}$ by Saier \& Roseman (1972).

Since HfrC strains of $E$. coli are galP $P^{+}$, the mutant tsi 9. I $\Delta$ could not be used directly to test the role of the PT system in the uptake of galactose by galP organisms. However, a cross of strain ts I9.I $\Delta$ with the $\mathrm{F}^{-}$strain K2.It gave recombinants that carried the ptsI crr deletion of the donor and, like the recipient, were both galP and $m g l$ : like strain K2.It (Fig. 1), these recombinants grew on galactose despite their inability to grow on glucose or fructose.

(iv) A similar recombinant (KRI05) was derived from the cross of strain tsi9.I $\Delta$ with the galK recipient KRIOO. Like other galK galP $\mathrm{mgl}$ mutants, this recombinant took up $0.2 \mathrm{mM}$ $\left[{ }^{14} \mathrm{C}\right]$ galactose slowly and only to the concentration present in the medium (cf. Figs. 3 and 4 ). However, when transduced to galK $^{+}$with phage PI propagated on the galP $m g l$ strain $\mathrm{K} 2.1 \mathrm{t}$, the organism grew on galactose but not on glucose or fructose. In contrast, recombinants 


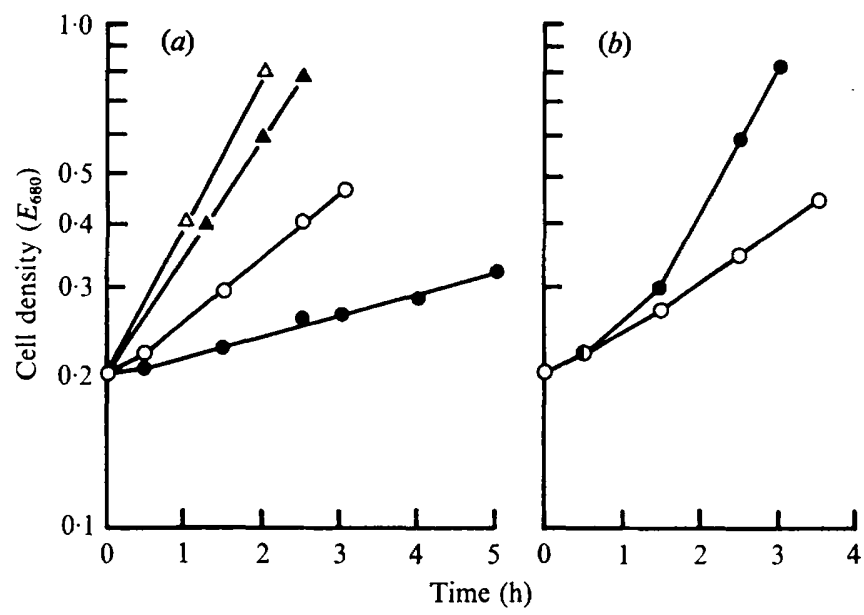

Fig. 9. Growth of strain K2.It $\left(u m g^{+}\right)$and of two of its mutants, differently impaired in Umg-function, on glucose (open symbols) and on galactose (closed symbols). (a) Strains K2.It $(\triangle, \Delta)$ and KRI64 $(\mathrm{O}, \bullet) ;(b)$ strain $\mathrm{KRI} 63(\mathrm{O}, \bullet)$.

derived from a cross of strain tsi9.I $\Delta$ with the umg recipient K2.I.22, which were galP $m g l$ umg as well as carrying the ptsI crr deletion, showed no growth on galactose-agar plates after 2 days at $37^{\circ} \mathrm{C}$.

These observations show that strains lacking the GalP and $\mathrm{Mgl}$ systems grow on galactose even though they lack phosphoenolpyruvate-phosphotransferase activity, but this growth occurs only if the product of the $u \mathrm{mg}^{+}$gene (or of a gene highly cotransducible with it) is also present. This implies that the $u \mathrm{mg}^{+}$(or closely linked) gene specifies a protein that can facilitate the diffusion of galactose into the cells without demanding the input of energy, either for concentrating the free sugar against a gradient or for converting the sugar to its phosphate ester. Further evidence is provided by experiments in which the efflux of $\left[{ }^{3} \mathrm{H}\right]-$ galactose was measured from $\mathrm{galK}$ cells that had taken up $\left[{ }^{3} \mathrm{H}\right]$ galactose either to a concentration above that present in the ambient medium (W4345: $\mathrm{galP}^{+} \mathrm{galK}$ ) or to a concentration equal to that in the medium (KRIO0:galP galK). As shown in Fig. 8(a), the efflux of labelled galactose from the galP+ strain occurred much more rapidly when the cells were diluted into medium containing unlabelled galactose than into medium containing salts only; in contrast, the galP cells lost the little labelled galactose they contained with equal rapidity when diluted into medium containing, or not containing, unlabelled galactose. The galP strain is thus unable to use energy to maintain a galactose concentration gradient; moreover, the total efflux of the internal galactose from these cells shows that the labelled sugar had not been phosphorylated during or after its uptake.

We conclude that galactose enters $E$. coli strains that are devoid of GalP and $\mathrm{Mgl}$ activity on a carrier that is also involved in the uptake of glucose and of its analogue methyl- $\alpha$-Dglucoside, but which, contrary to the generally-accepted view of sugar uptake by group translocation (Roseman, 1975), does not effect its simultaneous phosphorylation. This implies that glucose may also enter the cells by such a carrier and be phosphorylated in a subsequent step. Such a mechanism had been proposed by Roseman (I969), but abandoned by him and his co-authors largely on evidence obtained with Staphylococcus aureus: mutants devoid of PT-enzyme I are not able to equilibrate sugars in the medium with those in the cells (Simoni \& Roseman, 1973). However, from studies of the uptake of glucose and its analogues 


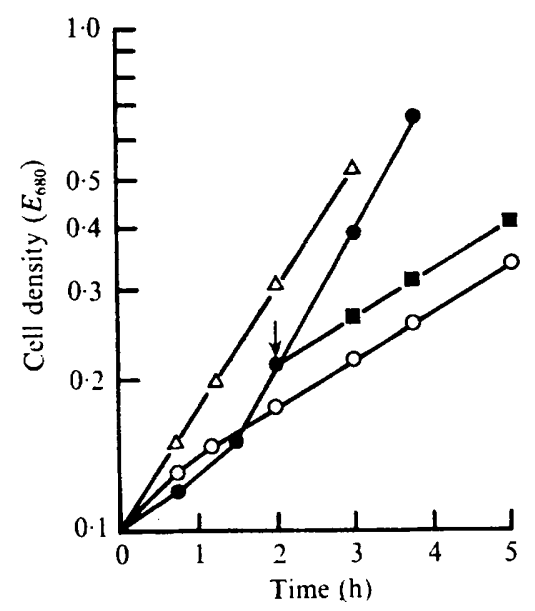

Fig. I0. The effect of glucose on the growth on galactose of strain KRI 63. Fructose-grown cells were used as inocula for growth on $10 \mathrm{~mm}$-fructose $(C), 10 \mathrm{~mm}$-glucose $(O)$, and Io mM-galactose $(\bullet)$. To one culture growing on galactose, $5 \mathrm{~mm}$-glucose was added at the time indicated by an arrow ( $(\mathbf{})$.

into $E$. coli strains, Gachelin (1970) concluded that phosphorylation of methyl- $x$-glucoside occurred after entry into the cell. More recently, Bourd et al. (1975) described E. coli mutants in which the transport of methyl- $\alpha$-glucoside by intact cells is low, but extracts of which contain normal phosphoenolpyruvate-phosphotransferase activities. This suggests impairment of a carrier protein involved in the facilitated diffusion (or active transport) of the sugar; this protein is postulated to be specified by a gene $\operatorname{tg} l$ that is closely linked to umg or is an allele of it.

Such an interpretation also accords with the growth properties of the mutant KRI63 (Fig. 9). Whereas the mutants K2.I.22 and KRI64 which do not blacken film after growth on nutrient agar in the presence of $10 \mu \mathrm{M}$-methyl- $\alpha$-D- $\left[{ }^{14} \mathrm{C}\right]$ glucoside and are thus severely impaired in the activity of the Umg system, grow less rapidly on either glucose or galactose than does their parent strain K2.It (Fig. I, Fig. 9a), strain KRI63 is impaired in its growth on glucose but not in its growth on galactose (Fig. $9 b$ ). Washed suspensions of this mutant, grown on $10 \mathrm{~mm}$-galactose, take up neither $10 \mu \mathrm{M}-\left[{ }^{14} \mathrm{C}\right]$ methyl- $\beta$-galactoside nor $0.5 \mu \mathrm{M}-\left[{ }^{14} \mathrm{C}\right]$ galactose, but take up $0.2 \mathrm{~mm}-\left[{ }^{14} \mathrm{C}\right]$ galactose at a rate and to an extent similar to the parent strain $\mathrm{K} 2 . \mathrm{It}$; however, methyl- $\alpha-\mathrm{D}-\left[{ }^{14} \mathrm{C}\right]$ glucoside uptake is severely impaired. Moreover, suspensions of strain KR I63 rendered permeable by toluene (Kornberg \& Reeves, I972) catalyse the phosphoenolpyruvate-dependent phosphorylation of methyl- $\alpha$ D-glucoside at less than $10 \%$ of the rate observed with similar suspensions of strain K2.It. The mutant KRI 63 is thus impaired in the phosphorylation step catalysed by this enzyme II complex, but (unlike other umg strains) is not affected in its ability to take up galactose; this continued utilization of galactose is not due to a change in the defective galP or $m g l$ genes. That it involves the entry of galactose via a system with high affinity for glucose is shown in Fig. I0. A fructose-grown culture of the mutant KRI 63 continued to grow rapidly after transfer to fresh medium containing fructose as sole carbon source, grew poorly on Io mM-glucose, and adapted to grow well on $10 \mathrm{~mm}$-galactose. However, when $5 \mathrm{~mm}$ glucose was added to a duplicate culture growing rapidly in 10 mM-galactose, the rate of growth speedily declined and was maintained at that characteristic of growth on glucose by these umg cells. Although glucose was taken up and utilized only poorly, its presence effectively blocked the utilization of the much better substrate galactose. 
We conclude that both galactose and glucose can be transported into galP $\mathrm{mgl}$ strains of $E$. coli by a carrier closely associated with the Umg system, but whereas glucose must be phosphorylated by the phosphoenolpyruvate-dependent enzymes specified by the umg gene (and by $p t s X$ ), galactose can be transported even in the absence of phosphotransferase activity. Our interpretation accords with the finding (Solomon, Miyai \& Lin, 1973) that the rapid efflux of labelled mannitol from ptsI mutants of $E$. coli occurs only if the enzyme II for that sugar is present, which bears out their prediction (Tanaka \& Lin, 1967) that an enzyme II complex may catalyse facilitated diffusion of its substrate across the membrane in the absence of phosphorylation.

Note added in proof: P. W. Postma (1976) reported results, and drew conclusions, from experiments with mutants of Salmonella typhimurium that are in agreement with those reported by us.

We thank Drs W. Boos, G. I. Bourd, M. C. Jones-Mortimer, A. Stouthamer and A. L Taylor for gifts of $E$. coli strains, Dr B. M. Wilkins for phage $\lambda c I 857$ and $\lambda$ vir, and the Science Research Council for support under grant B/SR/72462.

\section{REFERENCES}

Amaral, D. \& Kornberg, H. L. (1975). Regulation of fructose uptake by glucose in Escherichia coli. Journal of General Microbiology 90, I $57-168$.

Ashworth, J. M. \& KornberG, H. L. (1966). The anaplerotic fixation of carbon dioxide by Escherichia coli. Proceedings of the Royal Society B 165, 179-188.

Boos, W. (1969). The galactose binding protein and its relationship to the $\beta$-methylgalactoside permease from Escherichia coli. European Journal of Biochemistry 10, 66-73.

Bourd, G. I., Shabolenko, V. P., Andreeva, I. V., Klyutchova, V. V. \& Gershanovitch, V. N. (I969). Characteristics of the transport mutants of Escherichia coli with different defects in Roseman's phosphotransferase system. Molekulyarnaya Biologiya 3, 256-266.

Bourd, G. I., Bolshakova,\}T. N., Saprykina, T. P., Kiyutchova, V. V. \& Gershanovitch, V. N. (I971). Decrease of the rate of RNA and protein synthesis in the thermosensitive $E$. coli KI 2 mutant defective in the Roseman's phosphotransferase system. Molekulyarnaya Biologiya 5, 384-389.

Bourd, G. I., Erlagaeva, R. S., Bolshakova, T. N. \& Gershanovitch, V. N. (1975). Glucose catabolite repression in Escherichia coli $\mathrm{K} 12$ mutants defective in methyl- $\alpha-\mathrm{D}$-glucoside transport. European Journal of Biochemistry 53, 419-427.

Bray, G. A. (1960). A simple efficient liquid scintillator for counting aqueous solutions in a liquid scintillation counter. Analytical Biochemistry 1, 279-285.

BRICE, C. B. \& KoRnBERG, H. L. (I967). Location of a gene specifying phosphopyruvate synthase activity on the genome of Escherichia coli KI2. Proceedings of the Royal Society B 168, 28I-292.

Buttin, G. ( $1963 a$ ). Mecanismes regulateurs dans la biosynthèse des enzymes du metabolisme du galactose chez Escherichia coli KI2. I. La biosynthèse induite de la galactokinase et l'induction simultanée de la sequence enzymatique. Journal of Molecular Biology 7, 164-182.

Butrin, G. (1963 b). Mecanismes regulateurs dans la biosynthese des enzymes du metabolisme du galactose chez Escherichia coli $\mathbf{K} \mathbf{2}$. II. Le déterminisme genétique de la regulation. Journal of Molecular Biology 7, 183-205.

COOPER, R. A. \& KornBerg, H. L. (1967). The direct synthesis of phosphoenolpyruvate by Escherichia coli. Proceedings of the Royal Society B 168, 263-280.

Curtis, S. J. \& Epstein, W. (1970). Two constitutive P-HPr:glucose phosphotransferases in Escherichia coli KI 2. Federation Proceedings 30, I 123.

Epstein, W., Jewet, S. R. \& WINTER, R. H. (1970). Catabolite repression as basis of pleiotropy in PEPdependent phosphotransferase mutants of E. coli KI2. Federation Proceedings 29, 601 .

GaChelin, G. (1970). Studies on the $\alpha$-methylglucoside permease of Escherichia coli. A two-step mechanism for the accumulation of $\alpha$-methylglucoside 6-phosphate. European Journal of Biochemistry 16, 342-357.

HAROLD, F. M. (1972). Conservation and transformation of energy by bacterial membranes. Bacteriological Reviews 36, $172-230$.

Hestrin, S., Feingold, D. S. \& Schramm, M. (1955). Hexoside hydrolases. In Methods in Enzymology, vol. I, pp. 23I-257. Edited by S. P. Colowick and N. O. Kaplan. New York: Academic Press.

Horecker, B. L., Thomas, J. \& Monod, J. (1960). Galactose transport in E. coli. I. General properties studied with a galactokinaseless mutant. Journal of Biological Chemistry 235, $1580-1585$. 
Jones-MORTIMer, M. C. \& KORNBerg, H. L. (1974a). Genetic control of inducer exclusion by Escherichia coli. FEBS Letters 48, 93-95.

Jones-Mortimer, M. C. \& KornberG, H. L. (1974b). Genetical analysis of fructose utilization by Escherichia coli. Proceedings of the Royal Society $\mathrm{B}$ 187, 121-131.

KABACK, H. R. (1968). The role of the phosphoenolpyruvate-phosphotransferase system in the transport of sugars by isolated membrane preparations of Escherichia coli. Journal of Biological Chemistry 243, 371 1-3724.

Kalckar, H. M., Kurahashi, K. \& Jordan, E. (I959). Hereditary defects in galactose metabolism in Escherichia coli mutants. I. Determination of enzyme activities. Proceedings of the National Academy of Sciences of the United States of America 45, 1776-1 786.

Kamogawa, A. \& Kurahashi, K. (1967). Inhibitory effect of glucose on the growth of a mutant strain of Escherichia coli defective in glucose transport system. Journal of Biochemistry 6r, 220-230.

KORNBERG, H. L. (1972). Nature and regulation of hexose uptake by Escherichia coli. In The Molecular Basis of Biological Transport, pp. 157-180. Edited by J. F. Woessner, Jr. and F. Huijing. New York and London: Academic Press.

Kornberg, H. L. (1973). Fine control of sugar uptake by Escherichia coli. Symposia of the Society for Experinental Biology 27, 175-193.

Kornberg, H. L. \& Jones-Mortimer, M. C. (1975). Pts $X$ : a gene involved in the uptake of glucose and of fructose by Escherichia coli. FEBS Letters 51, I-4.

KornberG, H. L. \& ReEves, R. E. (1972). Inducible phosphoenolpyruvate-dependent hexose phosphotransferase activities in Escherichia coli. Biochemical Journal 128, $1339-1344$.

KornberG, H. L. \& SMITH, J. (1972). Genetic control of glucose uptake by Escherichia coli. FEBS Letters 20, $270-272$.

Kundig, W., Kundig, F. D., Anderson, B. E. \& Roseman, S. (1965). D-Galactose-6-phosphate synthesis by a phosphotransferase system. Federation Proceedings 24, 658 .

Lin, E. C. C. (1970). The genetics of bacterial transport systems. Annual Review of Genetics 4, $225-262$.

Miller, J. H. (1972). Experiments in Molecular Genetics. Cold Spring Harbor Laboratory.

Mrtchell, P. (1970). Membranes of cells and organelles: morphology, transport and metabolism. Symposia of the Society for General Microbiology 20, 121-166.

Mrtchell, P. (1973). Chemiosmotic coupling in energy transduction: a logical development of biochemical knowledge. Journal of Bioenergetics 4, 63-9I.

Morgan, M. J. \& KornBerg, H. L. (I967). Effect of pyruvate on hexose metabolism by Escherichia coli. Biochemical Journal 103, 57P.

Ordal, G. W. \& AdLER, J. (1974a). Isolation and complementation of mutants in galactose taxis and transport. Journal of Bacteriology II7, 509-516.

Ordal, G. W. \& Adler, J. (1974b). Properties of mutants in galactose taxis and transport. Journal of Bacteriology $117,517-526$.

Postma, P. W. (1976). Involvement of the phosphotransferase system in galactose transport in Salmonella typhimurium. FEBS Letters 61, 49-53.

Roberts, R. B., Abelson, P. H., Cowie, D. B., Bolton, E. T. \& Britten, R. J. (1955). Studies of Biosynthesis in Escherichia coli. Carnegie Institution of Washington Publication 607.

Roseman, S. (1969). The transport of carbohydrates by a bacterial phosphotransferase system. Journal of General Physiology 54, $138 \mathrm{~s}-180 \mathrm{~s}$.

Roseman, S. (1975). The bacterial phosphoenolpyruvate: sugar phosphotransferase system. Ciba Foundation Symposia 3I (new series), 225-24I.

Rotman, B., Ganesan, A. K. \& Guzman, R. (1968). Transport systems for galactose and galactosides in Escherichia coli. II. Substrate and inducer specificities. Journal of Molecular Biology 36, 247-26o.

SAIER, M. H. \& Roseman, S. (1972). Inducer exclusion and repression of enzyme synthesis in mutants of Salmonella typhimurium defective in enzyme I of the phosphoenolpyruvate: sugar phosphotransferase system. Journal of Biological Chemistry 247, 972-975.

Shimada, K., Weisberg, R. A. \& Gottesman, M. E. (1972). Prophage lambda at unusual chromosomal locations. I. Location of the secondary attachment sites and the properties of the lysogens. Journal of Molecular Biology 63, 483-503.

Simoni, R. D. \& Roseman, S. (1973). Sugar transport. VII. Lactose transport in Staphylococcus aureus. Journal of Biological Chemistry 248, 966-976.

Solomon, E., MiYaI, K. \& Lin, E. C. C. (1973). Membrane translocation of mannitol in Escherichia coli without phosphorylation. Journal of Bacteriology 144, 723-728.

TANAKA, S. \& LiN, E. C. C. (1967). Two classes of pleiotropic mutants of Aerobacter aerogenes lacking components of a phosphoenolpyruvate-dependent phosphotransferase system. Proceedings of the National Academy of Sciences of the United States of America 57, 913-919.

TAYlor, A. L. \& TROTTER, C. D. (1972). Linkage map of Escherichia coli strain KI 2. Bacteriological Revien's $36,504-524$.

VORISEK, J. \& KEPES, A. (1972). Galactose transport in Escherichia coli and the galactose-binding protein. European Journal of Biochemistry 28, 364-372. 
WANG, R. J. \& MORSE, M. L. (1968). Carbohydrate accumulation and metabolism in Escherichia coli. I. Description of pleiotropic mutants. Journal of Molecular Biology 32, 59-66.

WANG, R. J., MORSE, H. G. \& MORSE, M. L. (1970). Carbohydrate accumulation and metabolism in Escherichia coli: characteristics of the reversions of ctr mutations. Journal of Bacteriology 104, I3 1 8-1 324.

WILSON, D. B. (1974). The regulation and properties of the galactose transport system in Escherichia coli KI 2. Journal of Biological Chemistry 249, 553-558.

WINKLER, H. H. \& WILSON, T. H. (1966). The role of energy coupling in the transport of $\beta$-galactosides by Escherichia coli. Journal of Biological Chemistry 24I, 2200-22I I.

WU, H. C. P. (1967). Role of the galactose transport system in the establishment of endogenous induction of the galactose operon in Escherichia coli. Journal of Molecular Biology 24, 213-223. 